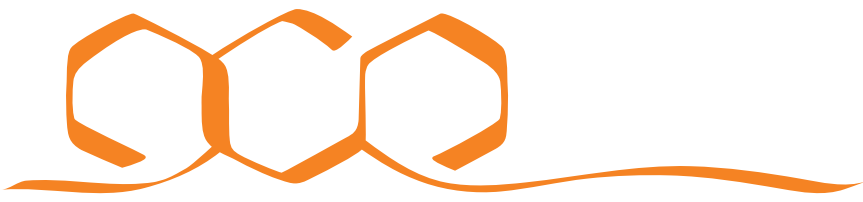 \\ COMMUNICATIONS CHEMISTRY
}

ARTICLE

\author{
https://doi.org/10.1038/s42004-020-00375-0 OPEN
}

\section{Zeolite-supported ultra-small nickel as catalyst for selective oxidation of methane to syngas}

Shuhei Yasuda (1) 1, Ryota Osuga1, Yusuke Kunitake1, Kazuya Kato², Atsushi Fukuoka (1) 2,

Hirokazu Kobayashi i ${ }^{2}$, Min Gao², Jun-ya Hasegawa², Ryo Manabe ${ }^{3}$, Hisashi Shima ${ }^{3}$, Susumu Tsutsuminai ${ }^{3}$ \& Toshiyuki Yokoi (1D ${ }^{1 凶}$

The development of simple catalysts with high performance in the selective oxidation of methane to syngas at low temperature has attracted much attention. Here we report a nickelbased solid catalyst for the oxidation of methane, synthesised by a facile impregnation method. Highly dispersed ultra-small $\mathrm{NiO}$ particles of $1.6 \mathrm{~nm}$ in size are successfully formed on the MOR-type zeolite. The zeolite-supported nickel catalyst gives continuously $97-98 \%$ methane conversion, $91-92 \%$ of $\mathrm{CO}$ yield with a $\mathrm{H}_{2} / \mathrm{CO}$ ratio of 2.0 , and high durability without serious carbon deposition onto the catalyst at $973 \mathrm{~K}$. DFT calculations demonstrate the effect of $\mathrm{NiO}$ particle size on the $\mathrm{C}-\mathrm{H}$ dissociation process of $\mathrm{CH}_{4}$. A decrease in the $\mathrm{NiO}$ particle size enhances the production of oxygen originating from the $\mathrm{NiO}$ nanoparticles, which contributes to the oxidation of methane under a reductive environment, effectively producing syngas.

\footnotetext{
${ }^{1}$ Institute of Innovative Research, Tokyo Institute of Technology, 4259 Nagatsuta, Midori-ku, Yokohama 226-8503, Japan. ${ }^{2}$ Institute for Catalysis, Hokkaido University, Kita 21 Nishi 10, Kita-ku, Sapporo 001-0021, Japan. ${ }^{3}$ Mitsubishi Chemical Corporation, 1000 Kamoshida-cho, Aoba-ku, Yokohama 227-8502,

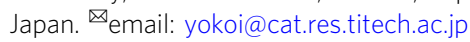


$\mathrm{M}$ ethane, the simplest alkane, is the principal component of natural gas and shale gas, which is a highly abundant and inexpensive carbon source of fuel and chemicals. Therefore, a development of the catalytic process that can directly convert methane into valuable chemicals leads to the effective use of methane as carbon source, and intensive efforts have been devoted to develop this catalytic process ${ }^{1-7}$. However, a technological breakthrough has been remained. The approach of conversion of methane to syngas is mostly based on steam reforming 8,9 and dry reforming ${ }^{10,11}$. These steam and dry reforming reactions are strongly endothermic; higher temperature and/or higher pressure of $\mathrm{CH}_{4}$ are required. On the other hand, neither higher temperature nor higher pressure is required for oxidation of methane to $\mathrm{CO}$ and $\mathrm{H}_{2}{ }^{12,13}$.

Recently, various catalysts with precious and/or nonprecious metals for selective oxidation of $\mathrm{CH}_{4}$ to $\mathrm{CO}$ and $\mathrm{H}_{2}$ productions have been proposed ${ }^{12-21}$. In previous work, Kobayashi et al. have

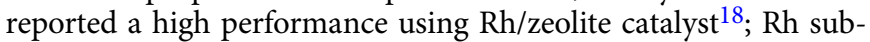
nano clusters are formed on the MOR-type zeolite and this $\mathrm{Rh} /$ MOR catalyst gave $84 \% \mathrm{CH}_{4}$ conversion and $91 \%$ selectivity for $\mathrm{CO}$ with $\mathrm{H}_{2} / \mathrm{CO}$ ratio of 2.0 at $873 \mathrm{~K}^{18}$. In addition, when cobalt was added to the catalyst, the catalytic performance was improved $^{19}$. Highly dispersed and mono-atomically controlled $\mathrm{Rh}$ species in Rh-Co/zeolite enhanced the reduction of Co species followed by the redox cycle of the catalyst, leading to the improvement.

Although various supported metal catalysts including $\mathrm{Rh}, \mathrm{Ni}$, and $\mathrm{Rh}-\mathrm{Ni}$, have been intensively developed for methane conversion, the catalytic application of supported $\mathrm{Ni}$ catalyst in the selective oxidation of methane to syngas has not been reported to date. Hence, the control of the Ni particle size and its effect on the performance have not been investigated to date. Furthermore, the mechanism of selective oxidation of methane to syngas over supported metal catalysts has not been completely clarified. The selective oxidation of methane is governed by the reaction equilibrium limitation involving $\mathrm{CH}_{4}, \mathrm{CO}, \mathrm{CO}_{2}, \mathrm{H}_{2}$, and $\mathrm{H}_{2} \mathrm{O}$. In order to achieve the production of syngas with a high yield at low temperature, the development of a novel catalyst that can overcome the equilibrium limitation has strongly been desired.

Here, a preparation method that can achieve the controls of the particle size of $\mathrm{Ni}$ species and its dispersion on zeolite has been developed based on the incipient wetness technique. Thus prepared zeolite-supported $\mathrm{Ni}$ catalyst is a highly active, selective and durable for oxidation of methane to syngas. In addition, DFT calculations demonstrate the size effect on the catalytic activity of $\mathrm{NiO}$ nanoparticles. Furthermore, the reaction mechanism involving lattice oxygen in ultra-small sized $\mathrm{NiO}$ species has been proposed.

\section{Results and discussion}

Size effect on the catalytic activity of $\mathrm{NiO}$ nanoparticles. It has been reported that the large size of Ni particle promotes decomposition of $\mathrm{CH}_{4}$, namely coke formation, in the absence of $\mathrm{O}_{2}{ }^{22}$. Very recently, the importance of Ni particle size on dry reforming and steam reforming of methane has been reported ${ }^{23}$. First, the effect of the loading amount of $\mathrm{Ni}$ was investigated; $\mathrm{Ni}(x) / \mathrm{MOR}-45$ was prepared with $x$ varied ranging from 0.5 to $5 \mathrm{wt} \%$ (Supplementary Fig. 1). The results are summarized in Supplementary Table 1 . The irregular change in the selectivity to $\mathrm{CO}$ over $\mathrm{Ni}(0.5) /$ MOR-45-evap and $\mathrm{Ni}(1) / \mathrm{MOR}-45$-evap would be due to the low conversion of $\mathrm{CH}_{4}$. Catalytic properties of the prepared samples were checked under the methane-rich reaction conditions, where coke resistance ability is easily evaluated. $\mathrm{Ni}(5) / \mathrm{MOR}-45$-evap showed a much lower catalytic performance than the catalyst prepared by the same method but having particle size of $3 \mathrm{~nm}[\mathrm{Ni}(3) /$
MOR-45-evap] (Fig. 1a). Moreover, Ni(5)/MOR-45-evap caused serious carbon deposition (21\% yield), indicating decomposition of $\mathrm{CH}_{4}$ on large $\mathrm{Ni}$ species. The effect of particle size including that within the same support (MOR-45), we prepared $\mathrm{Ni}(5) / \mathrm{MOR}-45-$ evap, $\mathrm{Ni}(3) / \mathrm{SiO}_{2}$-evap and $\mathrm{Ni}(3) / \mathrm{CeO}_{2}$-evap, having $\mathrm{Ni}$ species $15-25 \mathrm{~nm}$ in size, by a typical impregnation method based on the evaporation technique (Supplementary Fig. 2). For $\mathrm{Ni}(3) / \mathrm{SiO}_{2}$-evap and $\mathrm{Ni}(3) / \mathrm{CeO}_{2}$-evap, the conversions of $\mathrm{CH}_{4}$ were significantly low (ca. less than $1 \%$ ), and only slight amounts of $\mathrm{CO}_{2}$ were produced (Fig. 1b). Due to the very low activity, even coking did not occur. These results strongly give an insight about size-dependent activity relationships for the selective oxidation of $\mathrm{CH}_{4}$ to $\mathrm{CO}$ (Fig. 1c, d), though the influence of support might not be negligible.

DFT calculations were conducted to clarify the size effect on the catalytic activity of $\mathrm{NiO}$ nanoparticles. The $\mathrm{C}-\mathrm{H}$ dissociation process of $\mathrm{CH}_{4}$ was investigated because it has commonly been accepted as the first and a difficult step for oxidation of methane. The $\mathrm{NiO}$ surface and $\mathrm{NiO}$ cluster were chosen as the representative models for large- and small-sized $\mathrm{NiO}$ particles. It is known that the low Miller index surfaces, such as (100), (110), and (111) are stable and have been extensively considered in catalytic reactions. Here, we considered these three kinds of surfaces and compared their stabilities. The $\mathrm{NiO}(100)$ surface yields a nonpolar plane with the lowest surface energies, which means the $\mathrm{NiO}(100)$ surface would be the main facet for large size particles $^{24}$. Therefore, we chose $\mathrm{NiO}(100)$ surface as the computational model for the large sized particles.

As shown in Supplementary Fig. $3, \mathrm{CH}_{4}$ can bind weakly on the $\mathrm{NiO}(100)$ and $\mathrm{NiO}$ cluster with adsorption energies of -0.17 $\mathrm{eV}$ and $-0.13 \mathrm{eV}$, respectively. While the $\mathrm{C}-\mathrm{H}$ dissociation is endothermic on $\mathrm{NiO}(100)$ with the reaction energies of $1.7 \mathrm{eV}$, the reaction on $\mathrm{NiO}$ cluster is exothermic with the reaction energy of $-0.68 \mathrm{eV}$. After the $\mathrm{C}-\mathrm{H}$ dissociation, $\mathrm{CH}_{3}$ and $\mathrm{H}$ species formed the bonds with terrace $\mathrm{Ni}$ and $\mathrm{O}$ atoms of $\mathrm{NiO}$ (100) surface, but with the ones at edge/corner sites of $\mathrm{NiO}$ cluster. Compared to the terrace atoms, the edge/corner ones are low-coordinated and supposed to be more active. Thus, these calculations suggest that the ratio of edge/corner atoms over terrace atoms increases by decreasing the size of $\mathrm{NiO}$ nanoparticles, leading to the improvement of the catalytic activity.

Synthesis and reactivity of supported ultra-small Ni catalyst. The effect of the loading amount of $\mathrm{Ni}$ was investigated; $\mathrm{Ni}(x) /$ MOR-45 was prepared with $x$ varied ranging from 0.1 to $10 \mathrm{wt} \%$. All the samples of $\mathrm{Ni}(x) / \mathrm{MOR}-45$ had a highly crystalline MORtype structure (Fig. 2a). At $x=0.1-5$, the diffraction peaks attributed to $\mathrm{NiO}$ species were hardly observed, suggesting that the Ni species were highly dispersed on the surface of MOR- 45 . However, at $x=10$, the diffraction peaks attributed to the $\mathrm{NiO}$ species such as $2 \theta=43^{\circ}(200), 63^{\circ}(220), 75^{\circ}(311)$ and $79^{\circ}(222)$ planes were slightly observed ${ }^{25}$. $\mathrm{Ni}(5) / \mathrm{MOR}-45$ was reprehensively characterized by SEM and TEM observations. The SEM image revealed that bulky Ni particles were not observed on the surface of the zeolite (Fig. 3a). The TEM image was employed to determine the particle size of the $\mathrm{Ni}$ species, indicating that the particles with a mean size of $1.6 \mathrm{~nm}$ were highly distributed in the MOR zeolite(Fig. 3b and Supplementary Fig. 4). In combination with the EDX analyses (Supplementary Fig. 5), the Ni species were highly dispersed on the zeolite. As a control, $\mathrm{Ni}(x) / \mathrm{MOR}-45$ were prepared by a typical impregnation method based on the evaporation technique, and thus prepared samples were designated as "Ni( $(x) /$ MOR-45-evap" (Supplementary Fig. 1). At $x=3$, $\mathrm{Ni}$ particles $3 \mathrm{~nm}$ in size were formed. However, unlike the incipient wetness technique, the Ni loading of $5 \mathrm{wt} \%$ resulted in the formation of the Ni particles $17 \mathrm{~nm}$ in size (Supplementary 
(a)

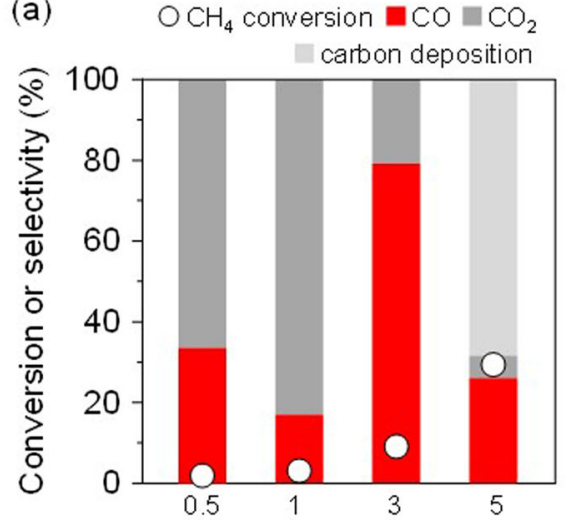

Loading amount of $\mathrm{Ni}(x) / \mathrm{MOR}-45$-evap (wt \%)

(c)

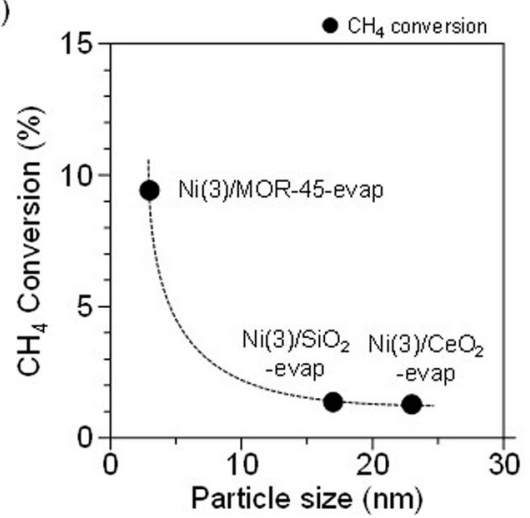

(b)

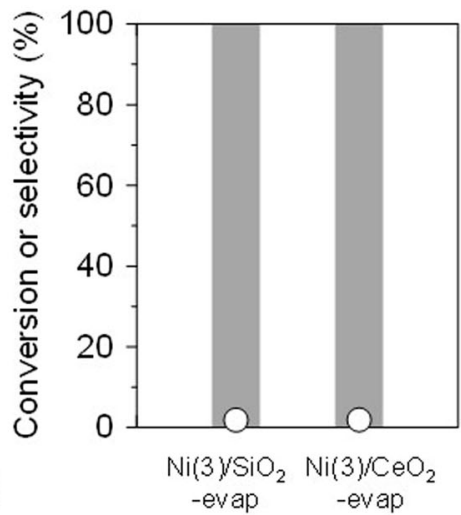

(d)

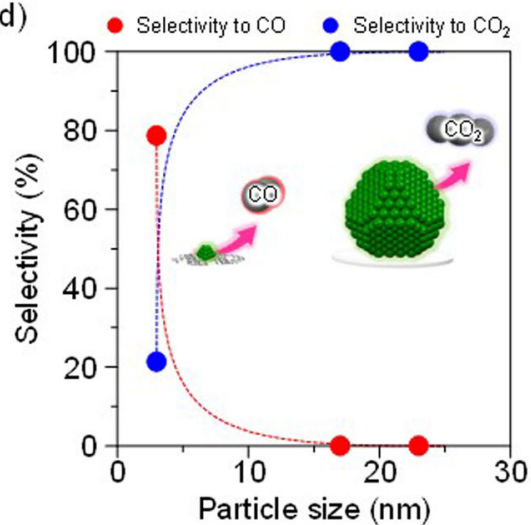

Fig. 1 Oxidation of methane over supported $\mathbf{N i}$ catalysts. a $\mathrm{Ni}(x) / \mathrm{MOR}-45$-evap and $\mathbf{b}$ metal oxides-supported $\mathrm{Ni}$ catalysts, $\mathrm{Ni}(3) / \mathrm{SiO}{ }_{2}$ and $\mathrm{Ni}(3) / \mathrm{CeO}$. (O) Conversion of methane, (red and gray) bars represent yield of $\mathrm{CO}$ and $\mathrm{CO}_{2}$, respectively. Reaction conditions: $\mathrm{CH}_{4}: \mathrm{O}_{2}: \mathrm{N}_{2}=0.50: 0.04: 0.46$ (atm); total pressure, $0.1 \mathrm{MPa}$; temperature, $873 \mathrm{~K}$; and SV $=6.0 \times 10^{4} \mathrm{~mL} \mathrm{~h}^{-1} \mathrm{~g}_{\text {-cat }}{ }^{-1}$. The catalytic performance plotted against Ni nanoparticle size for methane oxidation ((c) and $\mathbf{d})$ ). A second-order polynomial fit (broken-line) is drawn through the points as an eye guide. These catalytic results were summarized in Supplementary Table 1.

(a) Powder XRD patterns

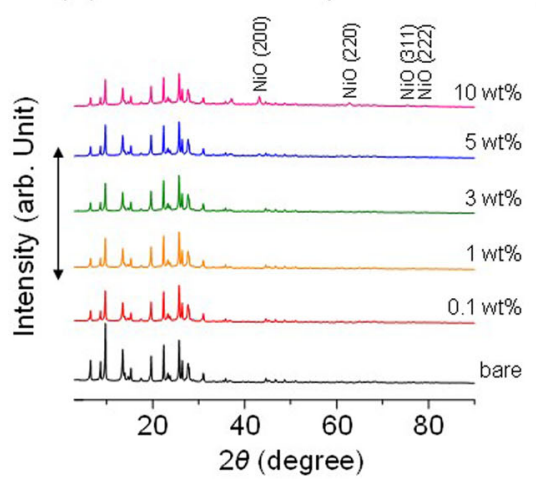

(b) Results of oxidation of methane

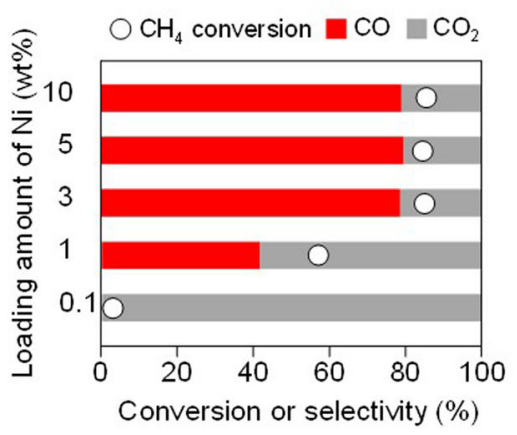

Fig. 2 Effect of the loading amounts of $\mathbf{N i}$ on MOR-45. a XRD patterns of $\mathrm{Ni}(x) / \mathrm{MOR}-45$ and $\mathbf{b}$ Oxidation of methane over Ni(x)/MOR-45: (O) Conversion of methane, (red and gray) bars represent the yields of $\mathrm{CO}$ and $\mathrm{CO}_{2}$, respectively. Reaction conditions: $\mathrm{CH}_{4}: \mathrm{O}_{2}: \mathrm{Ar}=0.06: 0.03: 0.91$ (atm); total pressure, $0.1 \mathrm{MPa}$; temperature, $873 \mathrm{~K}$; and SV $=3.0 \times 10^{4} \mathrm{~mL} \mathrm{~h}^{-1} \mathrm{~g}_{\text {-cat }}{ }^{-1}$. Catalytic data were taken after at least $3 \mathrm{~h}$ from the beginning of the reaction.

Table 1). These results clearly demonstrated that the incipient wetness technique is an effective method for the introduction of nano-sized and highly dispersed $\mathrm{Ni}$ species onto zeolite even at high loading.

The catalytic performance of thus prepared catalysts in oxidation methane with a $\mathrm{CH}_{4} / \mathrm{O}_{2}$ ratio of 2 , which is based on the stoichiometric ratio for syngas production $\left(\mathrm{CH}_{4}+1 / 2 \mathrm{O}_{2} \rightarrow\right.$
$\mathrm{CO}+2 \mathrm{H}_{2}$ ), were evaluated (Fig. 2b). The loading amount of $\mathrm{Ni}$ had a great impact on the catalytic performance. The conversion of $\mathrm{CH}_{4}$ was increased along with $x$, and it reached about $80 \%$ after $x=3$. The increase in $x$ also led to the decrease in the selectivity to $\mathrm{CO}_{2}$. $\mathrm{Ni}(5) / \mathrm{MOR}-45$ exhibited the highest performance; it gave $85 \%$ of the conversion of $\mathrm{CH}_{4}$ and $79.6 \%$ of the selectivity to $\mathrm{CO}$ with the $\mathrm{H}_{2} / \mathrm{CO}$ ratio, 2.3. When Ni loading was further increased 
(a)

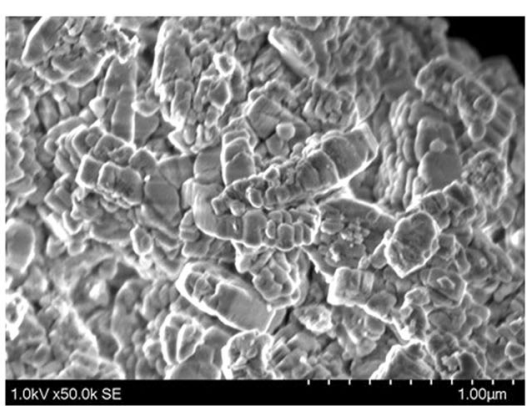

(b)

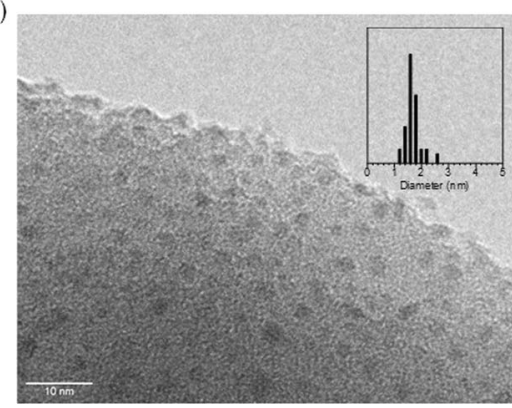

Fig. 3 Images of Ni(5)/MOR-45. a SEM and $\mathbf{b}$ TEM images.

to $10 \mathrm{wt} \%$, the conversion of $\mathrm{CH}_{4}$ was slightly increased to $82 \%$, but the selectivity to $\mathrm{CO}$ decreased to 78.9 with the $\mathrm{H}_{2} / \mathrm{CO}$ ratio of 2.2 compared to $\mathrm{Ni}(5) / \mathrm{MOR}-45$.

The influences of $\mathrm{Al}$ content in the zeolite on the state of $\mathrm{Ni}$ species loaded and the catalytic performance were investigated. The catalysts with the Si/Al ratio varied were prepared with the Ni loading amount kept $(x=5)$; the catalyst was designated as "Ni(5)/MOR-y," where $y$ was the $\mathrm{Si} / \mathrm{Al}$ ratio between 7.5 and 120 . There was little change in the X-ray diffraction (XRD) patterns of $\mathrm{Ni}(5) /$ MOR-y (Supplementary Fig. 6). The catalytic performance was not significantly influenced by the $\mathrm{Al}$ content in the zeolite; the conversion was about $82-84 \%$, and the selectivity to $\mathrm{CO}$ was $78-80 \%$ irrespective of $y$ (Supplementary Fig. 7). These results imply that the $\mathrm{Al}$ content is not a definitive factor for the formation of the active species. We also tested other zeolites including $\mathrm{Ni}(5) / \mathrm{MFI}-45$ and $\mathrm{Ni}(5) / \mathrm{FER}-10$ as a representative zeolite for methane oxidation (Supplementary Fig. 8). These catalysts gave almost the same catalytic performance as $\mathrm{Ni}(5)$ / MOR.

Here we showed you the advantages of the utilization of zeolite and the impact of $\mathrm{Ni}$ size on the catalytic performance. As a control, $5 \mathrm{wt} \%$ of $\mathrm{Ni}$ species were similarly loaded onto amorphous silica-alumina and silica; thus obtained catalysts were $\mathrm{Ni}(5) / \mathrm{SiO}_{2}-\mathrm{Al}_{2} \mathrm{O}_{3}$ and $\mathrm{Ni}(5) / \mathrm{SiO}_{2}$, respectively. In particular, the diffraction peaks attributed to $\mathrm{NiO}$ species $\mathrm{Ni}(5) / \mathrm{SiO}_{2}$ were clearly observed in the XRD pattern of $\mathrm{Ni}(5) / \mathrm{SiO}_{2}$ (Supplementary Fig. 9). Note that their catalytic performance showed lower than that of zeolite as the support (Supplementary Fig. 10). In the case of $\mathrm{Ni}(5) / \mathrm{SiO}_{2}-\mathrm{Al}_{2} \mathrm{O}_{3}, \mathrm{Ni}$-aluminate species such as $\mathrm{NiAl}_{2} \mathrm{O}_{4}$ were formed on the surface and it is considered to be inert to the reaction. There were no significant changes in the XRD patterns and ${ }^{27} \mathrm{Al}$ MAS NMR spectra of before and after the reaction at $873 \mathrm{~K}$ (Supplementary Fig. 11a, b), indicating that all the $\mathrm{Al}$ species remained intact in the MOR framework even after the reaction, and thus, the high stability of the $\mathrm{Al}$ species suppress the formation of the Ni-aluminate species. Furthermore, as a control, the utilizations of inert "silica" and "ceria" with redox property as support showed a low catalytic activity compared to Ni(5)/MOR45. Thus, we have concluded that acidic and base properties of support are not a definitive factor for this reaction, but the $\mathrm{NiO}$ particle size. These results imply that one of advantages of the utilization of zeolite is the control of the $\mathrm{Ni}$ species loaded, i.e., the formation of highly dispersed nano-sized $\mathrm{Ni}$ species, leading to a high catalytic performance. Thus our findings strongly indicate that the utilization of zeolite as support enables us to control of the size of $\mathrm{Ni}$ species and their dispersion that are critical factors for the partial oxidation of $\mathrm{CH}_{4}$ to syngas.

The temperature dependence of the reaction over Ni(5)/MOR45 between 673 and $1023 \mathrm{~K}$ was investigated (Fig. 4). The proportion of $\mathrm{CH}_{4}, \mathrm{CO}_{2}, \mathrm{CO}$, and $\mathrm{H}_{2}$ were considered based on thermodynamics by comparing with equilibrium composition. At
$673 \mathrm{~K}$, the conversions of $\mathrm{CH}_{4}$ and $\mathrm{O}_{2}$ were 2 and $5 \%$, respectively, and the production of $\mathrm{CO}$ was not observed; the main product was $\mathrm{CO}_{2}$ (selectivity was $>99 \%$ ), suggesting that only complete oxidation of methane to $\mathrm{CO}_{2}$ occurred. When the temperature raised to $723 \mathrm{~K}$, the conversions of $\mathrm{CH}_{4}$ and $\mathrm{O}_{2}$ were dramatically increased to about 50 and $100 \%$, respectively, and the yield of $\mathrm{CO}$ was $30 \%$. After $723 \mathrm{~K}$, the conversion of $\mathrm{CH}_{4}$ and yield of $\mathrm{CO}$ were gradually increased but the yield of $\mathrm{CO}_{2}$ was decreased along with the reaction temperature, and the proportion of $\mathrm{CH}_{4}, \mathrm{CO}_{2}, \mathrm{CO}$, and $\mathrm{H}_{2}$ became the equilibrium composition. When the reaction temperature was raised to $1023 \mathrm{~K}, 99 \%$ of the selectivity to $\mathrm{CO}$ with 2.0 of $\mathrm{H}_{2} / \mathrm{CO}$ ratio was achieved (CO yield $98-99 \%$ and $\mathrm{CH}_{4}$ conversion almost 100\%), meaning that the oxidation of $\mathrm{CH}_{4}$ stoichiometrically proceeded and the converted $\mathrm{CH}_{4}$ was transformed to $\mathrm{CO}$ and $\mathrm{H}_{2}\left(\mathrm{CH}_{4}+1 /\right.$ $2 \mathrm{O}_{2} \rightarrow \mathrm{CO}+2 \mathrm{H}_{2}$ ). In the $\mathrm{Rh} / \mathrm{MOR}$ catalyst, so-called "volcanotype behavior" was observed for the temperature dependence; the maximum activity was achieved at $873 \mathrm{~K}^{18}$. Thus, our catalyst is superior in the production of syngas from $\mathrm{CH}_{4}$ to the catalysts reported.

It is worth to note that the stability of the $\mathrm{Ni}(5) / \mathrm{MOR}-45$ catalyst was unprecedentedly high. It exhibited stable activity and selectivity for at least $1260 \mathrm{~min}$ at $873 \mathrm{~K}$. When the reaction temperature was $973 \mathrm{~K}$, the catalyst gave the highest conversion and selectivity, and the stable activity and selectivity to $\mathrm{CO}$ was kept for $8000 \mathrm{~min}$ (Fig. 5). The catalyst after the reaction was similarly characterized; the XRD pattern indicated that the crystallinity of the MOR zeolite was slightly decreased, and the SEM image revealed that the particle morphology was slightly destroyed but bulky $\mathrm{Ni}$ particles were not observed on the surface of the zeolite. Considering that the $\mathrm{Ni}(5) / \mathrm{MOR}-45$ catalyst exhibited a stable performance for a long time, we have considered that a slight decrease in the crystallinity did not affect the catalytic performance (Supplementary Figs. 12 and 13).

Mechanistic study on oxidation of methane over $\mathrm{Ni}$. The origin of oxygen introduced into the product, lattice oxygen atom or the oxygen adsorbed on surface, should be clarified to estimate the reaction mechanism. Based on computational chemistry, Nørskov et al. reported that lattice oxygen atom of $\mathrm{Ni}$ species plays a dominant role in redox reaction system ${ }^{26}$. It has been considered that, in $\mathrm{Rh}-\mathrm{Co} / \mathrm{MOR}$, the mono-atomically controlled $\mathrm{Rh}$ species with a high dispersion would enhance the reduction of Co species, accelerating the redox-cycle followed by the improvement of the catalytic performance. The oxygen species that can selectively oxidize $\mathrm{CH}_{4}$ to $\mathrm{CO}$ over $\mathrm{Ni}(5) / \mathrm{MOR}-45$ was investigated. We have adopted transient response experiments to investigate the influence of $\mathrm{O}_{2}$ in the reaction feed gas stream (Fig. 6). In the initial $235 \mathrm{~min}$, the reaction over $\mathrm{Ni}(5) / \mathrm{MOR}-45$ was conducted in the feed with $P_{\mathrm{O} 2}=0.03$ atm in steady-state, and then the reaction was switched to that with $P_{\mathrm{O} 2}=0$ atm. The reaction was 
(a)

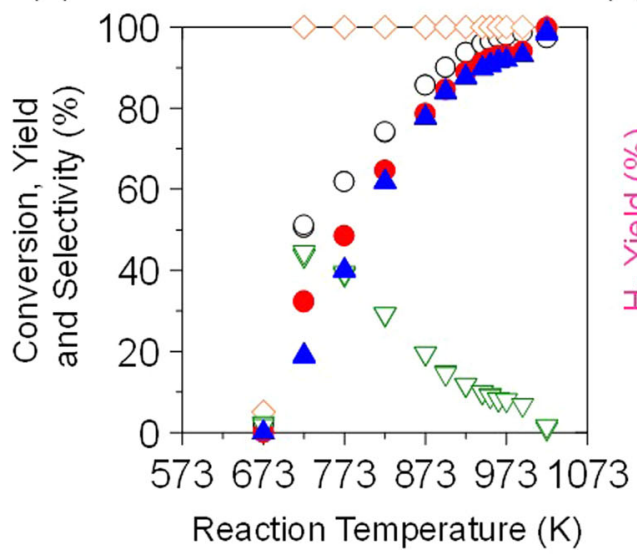

(b)

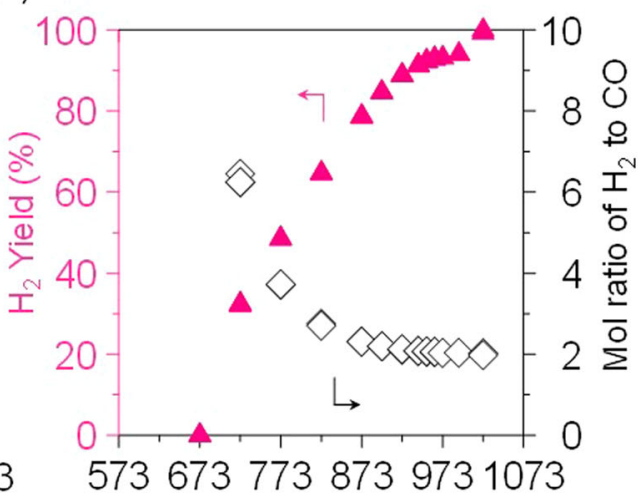

Reaction temperature $(\mathrm{K})$

Fig. 4 Effect of reaction temperature on the oxidation of methane to syngas over Ni(5)/MOR-45. a Conversions of $(O)$ methane and $(\diamond)$ oxygen, yields of $(\mathbf{O}) \mathrm{CO},(\nabla) \mathrm{CO}_{2}$, and $(\boldsymbol{\Delta})$ selectivity for CO. b $(\boldsymbol{\Delta})$ Yield of $\mathrm{H}_{2}$ and $(\diamond)$ mol ratio of $\mathrm{H}_{2}$ to CO. Reaction conditions: $\mathrm{CH}_{4}: \mathrm{O}_{2}: \mathrm{Ar}=0.06: 0.03: 0.91$ (atm); total pressure, $0.1 \mathrm{MPa}$; temperature, $673-1023 \mathrm{~K}$; and $\mathrm{SV}=3.0 \times 10^{4} \mathrm{~mL} \mathrm{~h}^{-1} \mathrm{~g}_{\text {-cat }}{ }^{-1}$.

(a)

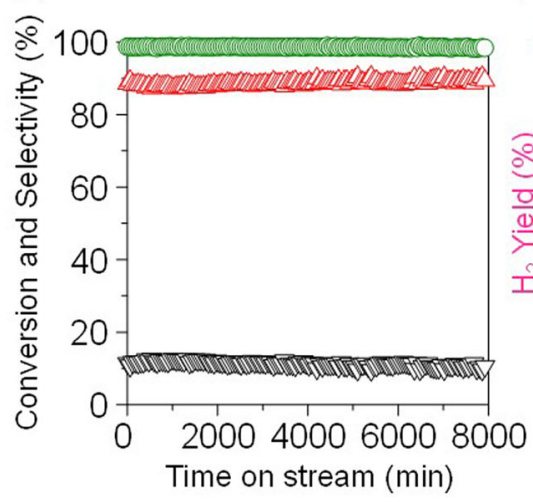

(b)

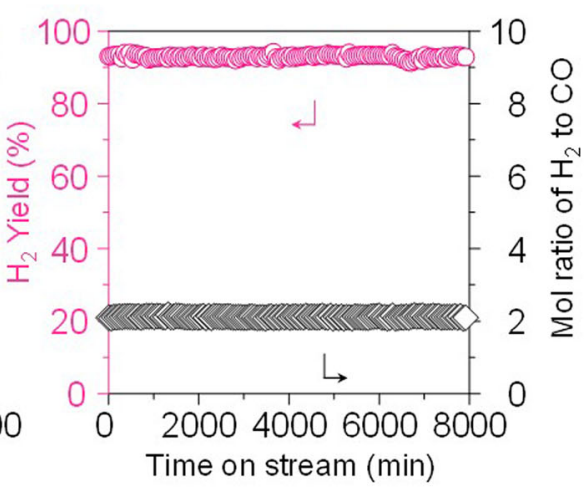

Fig. 5 Time courses for the oxidation of methane over Ni(5)/MOR-45. a $(\mathrm{O})$ Conversion of methane and selectivities for $(\triangle) \mathrm{CO}$ and $(\nabla) \mathrm{CO}{ }_{2} . \mathbf{b}(\mathrm{O})$ Yield of $\mathrm{H}_{2}$ and $(\diamond)$ mol ratio of $\mathrm{H}_{2}$ to $\mathrm{CO}$. Reaction conditions: $\mathrm{CH}_{4}: \mathrm{O}_{2}: \mathrm{Ar}=0.06: 0.03: 0.91(\mathrm{~atm})$; total pressure, $0.1 \mathrm{MPa}$; temperature, $973 \mathrm{~K}$; and $\mathrm{SV}=$ $3.0 \times 10^{4} \mathrm{~mL} \mathrm{~h}^{-1} \mathrm{~g}_{\text {-cat }}{ }^{-1}$. $97-98 \%$ methane conversion, $91-92 \%$ of $\mathrm{CO}$ yield with a $\mathrm{H}_{2} / \mathrm{CO}$ ratio of 2.0 without serious carbon deposition onto the catalyst.

continued even after the stop of $\mathrm{O}_{2}$ supply; the productions of $\mathrm{CO}$ and $\mathrm{H}_{2}$ were observed. Finally, the reaction completely stopped 120 min after the $\mathrm{O}_{2}$ supply was turned off. The fact implies that one of the reaction pathways is based on "Mars-van Krevelen mechanism", in which lattice oxygen of the $\mathrm{NiO}$ in $\mathrm{Ni} / \mathrm{MOR}$ can oxidize methane. To support this mechanism, the catalyst after the transient response reaction was characterized by XRD and Xray photoelectron (XPS) measurements in terms of the reduction degree of the Ni species. Supplementary Fig. 14 demonstrated that $\mathrm{Ni}^{0}$ species were clearly observed in the powder XRD patterns, while $\mathrm{NiO}$ species were less observed. It should be noted that the spectra due to $\mathrm{Ni} 2 \mathrm{p}_{1 / 2}$ and $\mathrm{Ni} 2 \mathrm{p}_{3 / 2}$ were shifted toward low binding energies (Supplementary Fig. 15). These changes support that the $\mathrm{NiO}$ was reduced to $\mathrm{Ni}$ when $\mathrm{CH}_{4}$ was oxidized to $\mathrm{CO}$. Furthermore, there was a difference in transient response between the $\mathrm{CO}$ and $\mathrm{CO}_{2}$ yields after the stop of $\mathrm{O}_{2}$ supply; the production of $\mathrm{CO}_{2}$ was drastically decreased, while that of $\mathrm{CO}$ was gradually decreased. Note that, at this transient response, the selectivity to $\mathrm{CO}$ and $\mathrm{H}_{2} / \mathrm{CO}$ ratio were continuously near $100 \%$ and 2.0, respectively even after stop of $\mathrm{O}_{2}$ supply. The $\mathrm{CO}_{2}$ produced under the feed with $\mathrm{O}_{2}$ might be produced by oxidation by the surface mobile oxygen species ${ }^{25}$. Based on $\mathrm{H}_{2}$-TPR results
(Supplementary Fig. 16), the surface oxygen species with a high mobility were found to be an oxidant in this methane oxidation, supporting the importance of the reduction conditions during the reaction.

In addition to $\mathrm{Ni}(5) / \mathrm{MOR}-45$ (Fig. 6), the transient response experiment for $\mathrm{Ni}(5) / \mathrm{SiO}_{2}$, which has $\mathrm{NiO}$ nanoparticles $15 \mathrm{~nm}$ in size, was carried out to clarify the effect of the $\mathrm{NiO}$ particles size (Supplementary Fig. 17). The result indicated that the reaction was continued even after the stop of $\mathrm{O}_{2}$ supply; the productions of $\mathrm{CO}$ and $\mathrm{H}_{2}$ were observed. However, it should be noted that the $\mathrm{H}_{2} / \mathrm{CO}$ ratio was increased from 2 to more than 4 , and that $\mathrm{CO}_{2}$ was also slightly produced. Thus observed differences between $\mathrm{Ni}(5) / \mathrm{MOR}-45$ and $\mathrm{Ni}(5) / \mathrm{SiO}_{2}$ suggest that the $\mathrm{NiO}$ particle size strongly affected the catalytic properties and that the decrease in the size enhanced the selective production of syngas from oxidation of methane.

In order to clarify the redox ability depending on the $\mathrm{NiO}$ particle size, we carried out the reaction of $\mathrm{CH}_{4}$ without $\mathrm{O}_{2}$ flow over $\mathrm{Ni}(5) / \mathrm{MOR}-45$ and $\mathrm{Ni}(5) / \mathrm{SiO}_{2}$ (Supplementary Fig. 18). There was no marked difference in the amount of consumed lattice oxygen originated from the $\mathrm{NiO}$ nanoparticles between $\mathrm{Ni}$ (5)/MOR-45 and $\mathrm{Ni}(5) / \mathrm{SiO}_{2}$. Note that $\mathrm{Ni}(5) / \mathrm{MOR}-45$ only 

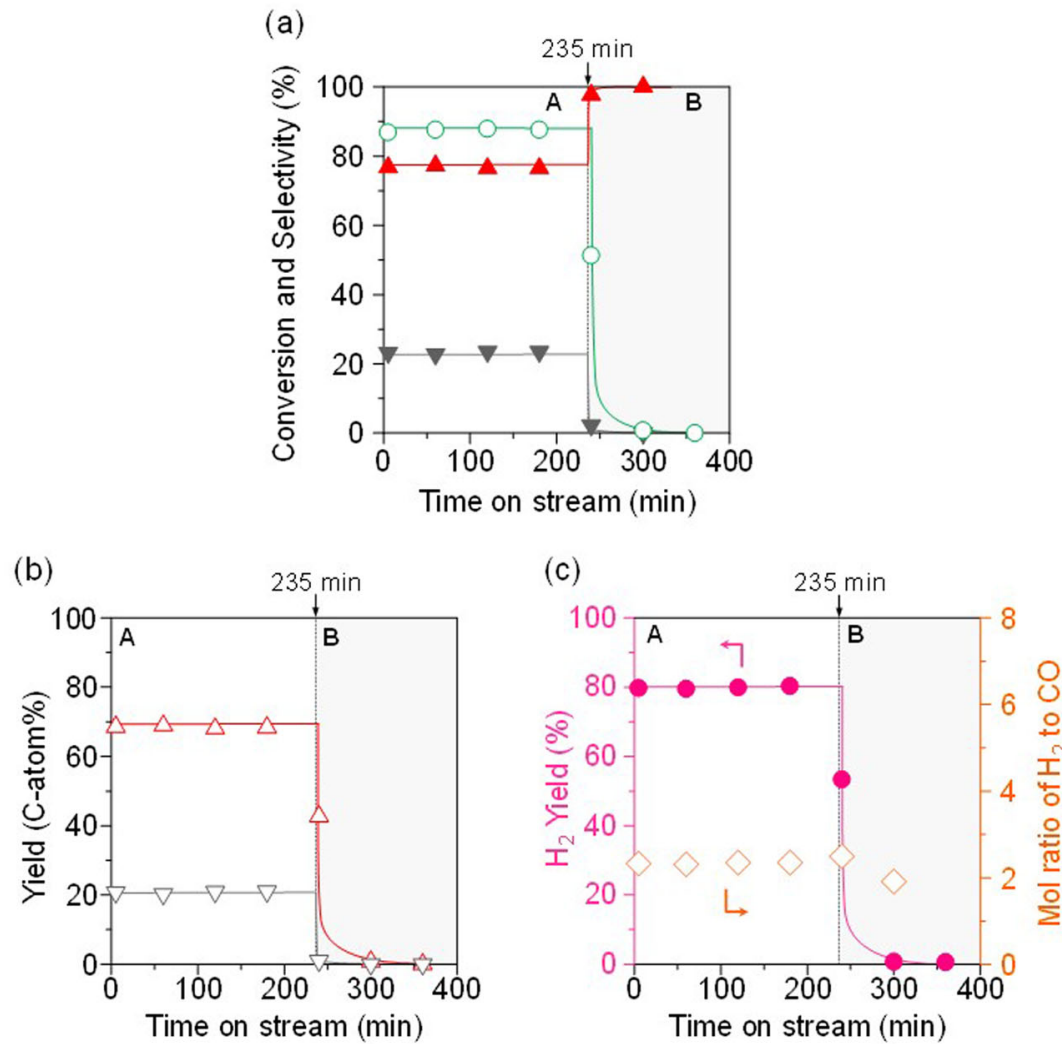

Fig. 6 Transient response for the oxidation of methane over Ni(5)/MOR-45 by changing the feed gas. The feed gas was changed from $A$, in the presence of $\mathrm{O}_{2}\left(P_{\mathrm{O}_{2}}=0.03 \mathrm{~atm}\right)$ to $\mathbf{B}$, in the absence of $\mathrm{O}_{2}\left(P_{\mathrm{O}_{2}}=0 \mathrm{~atm}\right)$ at $235 \mathrm{~min}$. a $(\mathrm{O})$ Conversion of methane and selectivities for $(\boldsymbol{\Delta}) \mathrm{CO}$ and $(\boldsymbol{\nabla})$ $\mathrm{CO}_{2}$. b Yields of $(\triangle) \mathrm{CO}$ and $(\nabla) \mathrm{CO}_{2} \cdot \mathbf{c}(\mathbf{O})$ Yield of $\mathrm{H}_{2}$ and $(\diamond)$ mol ratio of $\mathrm{H}_{2}$ to $\mathrm{CO}$. Reaction conditions: $\mathrm{CH}_{4}: \mathrm{O}_{2}: \mathrm{Ar}=(\mathbf{A})$ 0.06:0.03:balance $($ atm $)$, (B) 0.06:0:balance (atm); total pressure, $0.1 \mathrm{MPa}$; temperature, $873 \mathrm{~K}$; and SV $=3.0 \times 10^{4} \mathrm{~mL} \mathrm{~h}^{-1} \mathrm{~g}_{\text {-cat }}{ }^{-1}$.
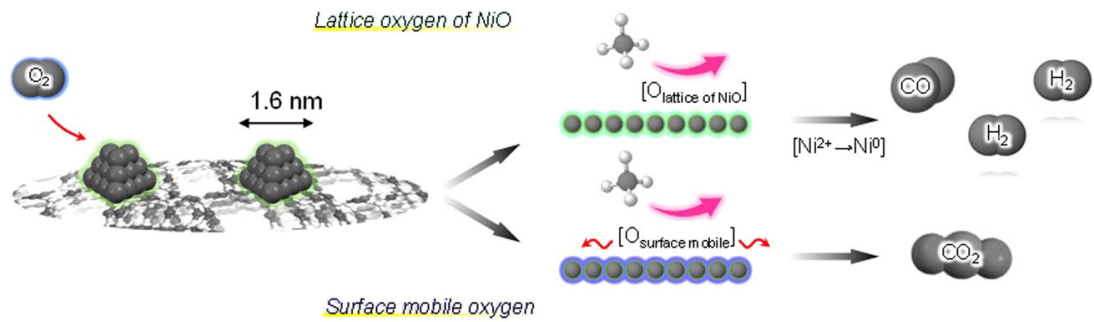

Fig. 7 Schematic illustration of possible reaction mechanism based on the effect of surface oxygen species on the reaction. Oxidized $\mathrm{CH}_{4}$ is completely converted to $\mathrm{CO}$ and $\mathrm{H}_{2}$ with the $\mathrm{H}_{2} / \mathrm{CO}=2.0$ in the absence of surface mobile oxygen.

produced $\mathrm{CO}$, while $\mathrm{Ni}(5) / \mathrm{SiO}_{2}$ produced $\mathrm{CO}_{2}$ as well as $\mathrm{CO}$, implying that $\mathrm{CO}$ formed is successively oxidized to $\mathrm{CO}_{2}$, and that the direct oxidation of $\mathrm{CH}_{4}$ to $\mathrm{CO}_{2}$ proceeded on the largesized $\mathrm{NiO}$ species. We have considered that the successive oxidation of $\mathrm{CO}$ to $\mathrm{CO}_{2}$ could be retarded by the reduction of the particle size of $\mathrm{NiO}$ species.

We estimated the amount of lattice oxygen in $\mathrm{Ni}(5) / \mathrm{MOR}-45$ on the assumption that all the $\mathrm{Ni}$ species are present as "NiO"; it was calculated to be $0.76 \mathrm{mmol} / \mathrm{g}$. Besides, the consumption of $\mathrm{H}_{2}$ in $\mathrm{H}_{2}$-TPR measurement was found to be $0.73 \mathrm{mmol} / \mathrm{g}$, being almost consistent with the amount of lattice oxygen originated from the $\mathrm{NiO}$ species. We carried out the reaction of $\mathrm{CH}_{4}$ without $\mathrm{O}_{2}$ flow over $\mathrm{Ni}(5) / \mathrm{MOR}-45$ of $50 \mathrm{mg}$, and then estimated the amount of oxygen used during the reaction by the amount of the product, $\mathrm{CO}$; the production of $\mathrm{CO}$ was found to be $16 \mu \mathrm{mol}$. The follows four reactions are the reactions involvement of oxygen in the oxidation of methane. Among them, if the production of $\mathrm{CO}$ is only based on Eq. (1), oxygen atom of $0.33 \mathrm{mmol} / \mathrm{g}$ is required to produce $\mathrm{CO}$ of $16 \mu \mathrm{mol}$. Besides, the amount of the remaining lattice oxygen in the catalyst after the reaction was calculated to be $0.36 \mathrm{mmol} / \mathrm{g}$ based on $\mathrm{H}_{2}$-TPR measurement. Hence, the total oxygen amount in the catalyst was estimated to be $0.69 \mathrm{mmol} / \mathrm{g}$ $(=0.33+0.36 \mathrm{mmol} / \mathrm{g})$. It should be noted that this value is almost accordance with that in the pristine catalyst (ca. $0.76 \mathrm{mmol} / \mathrm{g}$ ), meaning that $\mathrm{CH}_{4}$ was oxidized to $\mathrm{CO}$ by using the lattice oxygen; only Eq. (1) proceeded with $\mathrm{H}_{2} / \mathrm{CO}$ ratio of 2 .

$$
\begin{gathered}
\mathrm{CH}_{4}+[\mathrm{O}] \rightarrow \mathrm{CO}+2 \mathrm{H}_{2}, \\
\mathrm{H}_{2}+[\mathrm{O}] \rightarrow \mathrm{H}_{2} \mathrm{O}, \\
\mathrm{CO}+[\mathrm{O}] \rightarrow \mathrm{CO}_{2},
\end{gathered}
$$




$$
\mathrm{CH}_{4}+4[\mathrm{O}] \rightarrow \mathrm{CO}_{2}+2 \mathrm{H}_{2} \mathrm{O} \text {. }
$$

*[O]: lattice oxygen of $\mathrm{NiO}$ in the supported $\mathrm{Ni}$ catalyst.

Based on the results, a possible reaction mechanism for the partial oxidation of methane to syngas production over Ni/MOR has been proposed. Before starting the reaction, Ni/MOR has highly dispersed $\mathrm{NiO}$ species with $1.6 \mathrm{~nm}$ in size. In the initial stage, $\mathrm{CH}_{4}$ was oxidized by using lattice oxygen atoms derived from $\mathrm{NiO}$, and $\mathrm{NiO}$ was reduced to $\mathrm{Ni}\left(\mathrm{Ni}^{2+} \rightleftarrows \mathrm{Ni}^{0}\right)$. Oxidized $\mathrm{CH}_{4}$ was completely converted to $\mathrm{CO}$ and $\mathrm{H}_{2}$ with the $\mathrm{H}_{2} / \mathrm{CO}=$ 2.0 in the absence of surface mobile oxygen, i.e., reductive atmosphere (Fig. 7). Considering that this reaction did not proceed over $\mathrm{Co} / \mathrm{MOR}^{19}$, the redox ability of the $\mathrm{Ni}$ species is one of the essential factors for selectively producing syngas from selective oxidation of methane. In addition, the successive oxidation of $\mathrm{CO}$ to $\mathrm{CO}_{2}$ could be greatly retarded by reducing the size of the $\mathrm{NiO}$ species, leading to the selective production of $\mathrm{CO}$ and $\mathrm{H}_{2}$. Thus proposed mechanism based on via redox cycle of $\mathrm{NiO}$ without the assistance of any surface mobile oxygen species is novel and the first report.

In conclusion, we succeeded in controlling the size and dispersion of $\mathrm{Ni}$ species by using zeolite as support. Thus zeolite-supported ultra-small sized $\mathrm{Ni}$ exhibited a high catalytic performance in the selective oxidation of $\mathrm{CH}_{4}$ to $\mathrm{CO}$ and $\mathrm{H}_{2}$, and it showed a high durability without formation of coke. From transient response experiment, we have found that methane was oxidized by the lattice oxygen of $\mathrm{NiO}$ in $\mathrm{Ni}$ /zeolite and $\mathrm{CH}_{4}$ oxidation proceeds under reductive atmosphere. We believe that our findings would give us important insights on the catalytic conversion of $\mathrm{CH}_{4}$.

\footnotetext{
Methods

Catalysts preparation. Zeolite supported $\mathrm{Ni}$ catalyst was prepared by a facile impregnation method based on incipient wetness technique. When the MOR-type zeolite was used as zeolite, the catalyst was designated as $\mathrm{Ni}(x) / \mathrm{MOR}-y$, where $x$ and $y$ were $\mathrm{Ni}$ loading amount and the $\mathrm{Si} / \mathrm{Al}$ atomic ratio in zeolite, respectively. In a typical synthesis, the proton-type MOR-type zeolite with the Si/Al ratio of 45 (MOR-45, JRC-Z-HM90) was obtained from the Catalysis society of Japan(CSJ). Ni $\left(\mathrm{NO}_{3}\right)_{2}(0.45 \mathrm{mmol})$ was dissolved in $10 \mathrm{~mL}$ of water. This solution was dropwisely added onto the MOR $(0.5 \mathrm{~g})$, and then the resulting wet solid was dried in air at $373 \mathrm{~K}$, following calcination in air at $873 \mathrm{~K}$ for $6 \mathrm{~h}$ (rate of temperature increase, $10 \mathrm{~K} \mathrm{~min}^{-1}$ ).
}

Catalysts characterization. Powder XRD patterns were recorded on a RINTUltima III (Rigaku) using a Cu Ka X-ray source $(40 \mathrm{kV}, 40 \mathrm{~mA})$. XPS spectra were taken by using a ULVAC-PHI ESCA 1700R (Al Ka radiation). Binding energy was calibrated with respect to $\mathrm{C} 1 \mathrm{~s}$ peak of a carbon tape at $284.8 \mathrm{eV}$. Field-emission scanning electron microscopic images of the powder samples were obtained on a Hitachi SU9000 microscope operated at $1 \mathrm{kV}$. TEM images of the powder samples were obtained on a JEOL JEM-2010F. ${ }^{27} \mathrm{Al}$ MAS NMR spectra were obtained on a JEOL ECA-600 spectrometer. Elemental analyses of the samples were performed on an inductively coupled plasma-atomic emission spectrometer (ICP-AES, Shimadzu ICPE-9000)

Catalytic oxidation of methane. Catalytic oxidation of methane was performed in a continuous flow reactor under atmospheric pressure. After pretreatment of the catalyst $\left(50 \mathrm{mg}\right.$ ) at $873 \mathrm{~K}$ with $\mathrm{Ar}$ at the flow rate of $30 \mathrm{~mL} \mathrm{~min}^{-1}$ for $1 \mathrm{~h}$, the mixture gas of $\mathrm{CH}_{4}(0.06 \mathrm{~atm}), \mathrm{O}_{2}(0.03 \mathrm{~atm}), \mathrm{Ar}$ (balance) at an SV $3.0 \times 10^{4} \mathrm{~mL} \mathrm{~h}^{-1} \mathrm{~g}_{\text {-cat }}{ }^{-1}$ was fed into the reactor. The temperature inside the catalyst bed was monitored using thermocouple. The reaction products at the outlet of the reactor were analyzed by using on-line gas chromatography. $\mathrm{CH}_{4}, \mathrm{CO}, \mathrm{H}_{2}$, and $\mathrm{CO}_{2}$ were analyzed by GC (Shimadzu, GC-2014) equipped with a thermal conductivity detector and packed column (Shimadzu, Shincarbon-ST 50/80, inner diameter $3 \mathrm{~mm}$, length $6 \mathrm{~m}$ ). For other products such as ethane and ethene, the other GC (Shimadzu, GC-2014) equipped flame ionization detector and a capillary column (Agilient, HP-PLOT Q, inner diameter $0.530 \mathrm{~mm}$, length $30 \mathrm{~m}$, film thickness $40.0 \mu \mathrm{m}$ )

\section{Data availability}

The authors declare that all data supporting the findings of this study are available within the paper and its supplementary information files.
Received: 13 April 2020; Accepted: 17 August 2020;

Published online: 16 September 2020

\section{References}

1. Hammond, C., Conrad, S. \& Hermances, I. Oxidative methane upgrading ChemSusChem. 5, 1668-1686 (2012).

2. Guo, X. et al. Direct, nonoxidative conversion of methane to ethylene, aromatics, and hydrogen. Science 344, 616-619 (2014).

3. Sushkevich, V. L., Palagon, D., Ranocchiari, M. \& Bokhoven, J. Avan Selective anaerobic oxidation of methane enables direct synthesis of methanol. Science 356, 523-527 (2017).

4. Rofer-DePoorter, C. K. A comprehensive mechanism for the Fischer-Tropsch synthesis. Chem. Rev. 81, 447-474 (1981).

5. Li, J. et al. Integrated tuneable synthesis of liquid fuels via Fischer-Tropsch technology. Nat. Catal. 1, 787-793 (2018).

6. Böller, B., Durner, K. M. \& Wintterlin, J. The active sites of a working Fischer-Tropsch catalyst revealed by operando scanning tunnelling microscopy. Nat. Catal. 2, 1027-1034 (2019).

7. Wang, P. et al. Synthesis of stable and low- $\mathrm{CO}_{2}$ selective $\varepsilon$-iron carbide Fischer-Tropsch catalysts. Sci. Adv. 4, eaau2947 (2018).

8. Van Hock, J. P. Methane-steam reforming. Catal. Rev. Sci. Eng. 21, 1-51 (1980).

9. Lulianeli, A., Liguori, S., Wilcox, J. \& Basile, A. Advances on methane steam reforming to produce hydrogen through membrane reactors technology: A review. Catal. Rev. Sci. Eng. 58, 1-35 (2016).

10. Abdulrasheed, A. et al. A review on catalyst development for dry reforming of methane to syngas. Renew. Sustain. Energy Rev. 108, 175-193 (2019).

11. Chein, R.-Y. \& Fung, W.-Y. Syngas production via dry reforming of methane over $\mathrm{CeO}_{2}$ modified $\mathrm{Ni} / \mathrm{Al}_{2} \mathrm{O}_{3}$ catalysts. Int. J. Hydrog. Energy 44, 14303-14315 (2019)

12. Enger, B. C., Lødeng, R. \& Holmen, A. A review of catalytic partial oxidation of methane to synthesis gas with emphasis on reaction mechanisms over transition metal catalysts. Appl. Catal. A. Gen. 346, 1-27 (2008).

13. Alvarez-Galvan, C. et al. Partial oxidation of methane to syngas over nickelbased catalysts: influence of support type, addition of rhodium, and preparation method. Front. Chem. 7, 104 (2019).

14. Ashcroft, A. T. et al. Selective oxidation of methane to synthesis gas using transition metal catalysts. Nature 344, 319-321 (1990)

15. Dissanayake, D., Rosynek, M. P., Kharas, K. C. C. \& Lunsford, J. H. Partial oxidation of methane to carbon monoxide and hydrogen over a $\mathrm{Ni} / \mathrm{Al}_{2} \mathrm{O}_{3}$ catalyst. J. Catal. 132, 117-127 (1991).

16. Choudhary, V. R., Rajput, A. M. \& Prabhakar, B. Nonequilibrium oxidative conversion of methane to $\mathrm{CO}$ and $\mathrm{H}_{2}$ with high selectivity and productivity over Ni/ $\mathrm{Al}_{2} \mathrm{O}_{3}$ at low temperatures. J. Catal. 139, 326-328 (1993).

17. Torniainen, P. M., Chu, X. \& Schmidt, L. D. Comparison of monolithsupported metals for the direct oxidation of methane to syngas. J. Catal. 146, $1-10$ (1994).

18. Hou, Y., Ogasawara, S., Fukuoka, A. \& Kobayashi, H. Zeolite-supported rhodium sub-nano cluster catalyst for low-temperature selective oxidation of methane to syngas. Catal. Sci. Technol. 7, 6132-6139 (2017)

19. Hou, Y., Nagamatsu, S., Asakura, K., Fukuoka, A. \& Kobayashi, H. Trace mono-atomically dispersed rhodium on zeolite-supported cobalt catalyst for the efficient methane oxidation. Commun. Chem. 1, 41 (2018)

20. Jin, R. et al. Mechanism for catalytic partial oxidation of methane to syngas over a Ni/ $\mathrm{Al}_{2} \mathrm{O}_{3}$ catalyst. Appl. Catal. A. Gen. 201, 71-80 (2000).

21. Osuga, R. et al. Metal cation-exchanged zeolites with the location, state, and size of metal species controlled. Chem. Commun. 56, 5913-5916 (2020).

22. Takenaka, S., Kobayashi, S., Ogihara, H. \& Otsuka, K. Ni/SiO ${ }_{2}$ catalyst effective for methane decomposition into hydrogen and carbon nanofiber. $J$. Catal. 217, 79-87 (2003).

23. Vogt, C., Kranenborg, J., Monai, M. \& Weckhuysen, B. M. Structure sensitivity in steam and dry methane reforming over nickel: activity and carbon formation. ACS Catal. 10, 1428-1438 (2020).

24. Barmparis, G. D., Lodziana, Z., Lopez, N. \& Remediakis, I. N. Nanoparticle shapes by using Wulff constructions and first-principles calculations. Beilstein J. Nanotechnol. 6, 361-368 (2015).

25. Richardson, J. T., Scates, R. \& Twigg, M. V. X-ray diffraction study of nickel oxide reduction by hydrogen. Appl. Catal. A. Gen. 246, 137-150 (2003).

26. Nørskov, J. K. et al. Origin of the overpotential for oxygen reduction at a fuelcell cathode. J. Phys. Chem. B 108, 17886-17892 (2004).

\section{Acknowledgements}

This work was partially supported by Cross-ministerial Strategic Innovation Promotion Program (SIP) organized by Cabinet Office, Government of Japan and by Japan Science 
and Technology Agency (JST) CREST Grant Number JPMJCR15P4. The computational part is also supported by the JSPS KAKENHI(JP20K05217) and by supercomputer at RCCS, Okazaki, Japan. A.F., H.K., M.G., J.H. acknowledge the MEXT project, “Integrated Research Consortium on Chemical Sciences".

\section{Author contributions}

S.Y. performed methane oxidation and characterization. K.K. performed a part of methane oxidation. M.G. performed DFT calculations. Y.K., R.O., A.F., H.K., M.G., J.H., R.M., H.S., and S.T. discussed all results. S.Y. and T.Y. wrote the manuscript. T.Y. conducted the project.

\section{Competing interests}

The authors declare no competing interests.

\section{Additional information}

Supplementary information is available for this paper at https://doi.org/10.1038/s42004020-00375-0

Correspondence and requests for materials should be addressed to T.Y.
Reprints and permission information is available at http://www.nature.com/reprints

Publisher's note Springer Nature remains neutral with regard to jurisdictional claims in published maps and institutional affiliations.

(c) (i) Open Access This article is licensed under a Creative Commons Attribution 4.0 International License, which permits use, sharing, adaptation, distribution and reproduction in any medium or format, as long as you give appropriate credit to the original author(s) and the source, provide a link to the Creative Commons license, and indicate if changes were made. The images or other third party material in this article are included in the article's Creative Commons license, unless indicated otherwise in a credit line to the material. If material is not included in the article's Creative Commons license and your intended use is not permitted by statutory regulation or exceeds the permitted use, you will need to obtain permission directly from the copyright holder. To view a copy of this license, visit http://creativecommons.org/ licenses/by/4.0/.

(C) The Author(s) 2020 